\title{
Coulisses
}

Revue de théâtre

\section{Rencontre avec le théâtre Nô}

Jeudi 25 septembre 2008 à la Maison de l'UNESCO, Paris

\section{Régis Fougère}

\section{OpenEdition}

\section{Journals}

Édition électronique

URL : https://journals.openedition.org/coulisses/896

DOI : $10.4000 /$ coulisses.896

ISSN : 2546-9460

Éditeur

Presses universitaires de Franche-Comté

\section{Édition imprimée}

Date de publication : 31 décembre 2010

Pagination : 11-16

ISBN : 978-2-84867-302-8

ISSN : $1150-594 \mathrm{X}$

\section{Référence électronique}

Régis Fougère, " Rencontre avec le théâtre Nô », Coulisses [En ligne], 41 | Automne 2010, mis en ligne le 30 novembre 2016, consulté le 29 décembre 2022. URL : http://journals.openedition.org/coulisses/ 896 ; DOI : https://doi.org/10.4000/coulisses.896 


\title{
Rencontre avec le théâtre Nô
}

\author{
Jeudi 25 septembre 2008 à la Maison de l'UNESCO, Paris
}

\section{Régis Fougère}

1 Le nô est un art théâtral difficile à percevoir pour un occidental. Régulièrement - mais trop rarement - le public français peut aller à la rencontre de cet art ancestral dont les spécificités et la richesse sont susceptibles de le toucher. Cela nécessite cependant une initiation et quelques explications préalables.

2 Issu de la culture populaire, le nô connaît grâce à Zeami (1363-1384) - qui lui donne « sa forme épurée et définitive ${ }^{1} »-$ un grand succès. On lui doit une centaine de pièces et plusieurs traités qui définissent son art.

3 Une pièce de nô se fonde essentiellement sur de la danse et de la musique, avec quelques parties dialoguées. Le nô est construit autour du personnage principal (le shite), toujours masqué, auquel répond un autre personnage (le waki). Le shite interprète les parties lyriques et exécute la danse finale. Le chœur et les musiciens accompagnent et amplifient la voix de l'acteur.

4 Traditionnellement, on classe les pièces de nô en cinq catégories :

- les pièces d'apparat qui célèbrent un dieu, une divinité ;

- les pièces de guerriers ;

- les pièces de femmes ;

- les pièces du monde présent (y compris les pièces de « folles »);

- les pièces de fantômes ou démons.

Le nô puise ses origines dans des cérémonies, des rituels qui se déroulaient dans des temples. Le shite peut être ainsi perçu comme l'intermédiaire entre les dieux et les hommes. Le nô a toujours été plutôt réservé à une élite. Son raffinement, son hermétisme, ses conventions, sa symbolique en font un art littéraire dont il n'est pas toujours facile de percevoir les subtilités. Art de la lenteur et de la profondeur, le nô est aussi l'art dramatique japonais dont le raffinement et les émotions suscitées ravissent un public connaisseur. 
Koïchiro Matsura, Directeur général de l'Organisation des Nations Unies pour l'éducation, la science et la culture, avec le soutien de la Délégation permanente du Japon auprès de l'UNESCO et de la Fondation du Japon ainsi que du concours de la Maison de la culture du Japon à Paris.

7 Le théâtre nô va être essentiellement présenté par Haruhisa Kawamura (Trésor culturel vivant du Japon). Il est accompagné de quatre acteurs et de trois musiciens de sa troupe. La soirée verra alterner extraits de pièces et commentaires de Haruhisa Kawamura. Accompagné par une traductrice, c'est avec beaucoup de pédagogie, d'humour et de gentillesse qu'il va séduire un public venu en nombre et très attentif à l'initiation prodiguée.

C'est par un premier extrait de Takasago que débute cette rencontre, pièce sur un jeune dieu, Sumiyoshi. Entre les extraits, Haruhisa Kawamura va donner aux spectateurs quelques clés pour mieux comprendre le nô.

\section{Acteurs}

- Haruhisa KAWAMURA ;

- Madoka MIKATA ;

- Kazuaki KAWAMURA ;

- Haruna KaWAMURA ;

- Kaho KaWAmura.

Il expliquera tout d'abord que les pièces de nô sont marquées par le contexte religieux comme dans ce premier extrait. Le nô met en scène les rapports entre les dieux et les hommes. Cette pièce est souvent jouée pendant les cérémonies religieuses.

Il va ensuite expliquer la présence sur scène des quatre piliers : ce sont des vestiges du lieu ancestral puisque les représentations se déroulaient dans la cour des temples, sous un toit soutenu par des piliers. Mais ceux-ci ont un autre intérêt, ils sont des repères pour l'acteur masqué du nô qui ne perçoit l'espace théâtral que par de petits trous. Ainsi il pouvait éviter la chute de la scène. La disposition en carré, les hauts piliers créent aussi une profondeur de scène significative car les postures sont importantes.

La posture est en effet fondamentale. Elle détermine le type de personnage. Haruhisa Kawamura gratifie alors le public d'une démonstration. Le guerrier par exemple est toujours de face, les jambes écartées, démarche qu'il accentue lorsqu'il se déplace. Le déplacement est un art subtil dans le théâtre nô. C'est ce que nous montre Haruhisa Kawamura: il faut se pencher vers l'avant, le poids vers le bas, notamment dans les talons arrières. Il précise avec humour qu'il a mis vingt ans pour apprendre ce déplacement. Pour que le public saisisse ce mouvement il évoque le jardin japonais : à l'opposé de la culture française qui privilégie l'élévation de l'eau comme à Versailles, il s'agit de rentrer dans la terre. Le poids vers l'avant symbolise par ailleurs une puissance qui est dirigée vers le public.

13 Il ajoute enfin que la gestuelle dans le théâtre nô est stylisée. Au lieu d'un geste commun, l'acteur va magnifier ce qu'il exécute. Afin de mieux se faire comprendre, Haruhisa Kawamura saisit un éventail qu'il manipule un peu grossièrement puis, avec des gestes précis et raffinés, il le fait évoluer d'une manière prodigieuse (rappelons que dans le théâtre nô tous les rôles sont jouées par des hommes). 
14 L'extrait suivant provient de la pièce Sumidagawa, pièce dans laquelle une femme qui a perdu son enfant exprime sa douleur et son désespoir. Dès le XIv siècle, le théatre nô, s'inspirant entre autres de rituels et d'histoires anciennes, va privilégier - avec Zeami l'émotion esthétique dans un monde plus humanisé.

15 Haruhisa Kawamura s'attarde ensuite un peu plus sur l'extrait suivant. La pièce s'intitule Izutsu. Elle est inspirée par les Contes d'Ise du xe siècle. Il s'agit d'une " pièce de femme ». Zeami n'a pas repris complètement le conte. Deux enfants jouent autour d'un puits. Adultes, ils se marient. Mais l'homme est infidèle. Patiemment la femme attend son retour. C'est l'automne. Les herbes sont hautes. Elle est triste. En quelques éléments s'impose l'atmosphère si particulière du nô, entre rêve et réalité. Interrogée par un moine, elle se présente comme un esprit et danse dans les habits de son mari avec un éventail. Elle retrouve ainsi sa jeunesse et son amour perdu. Ses émotions demeurent tandis que l'on entend les cloches d'un temple et que le soleil s'apprête à se lever. Elle disparaît alors.

16 La pièce suivante, Kiyotsune, raconte la lutte entre les clans Taira et Minamoto. Kiyotsune est parti pour la guerre et il a laissé sa femme à Kyoto. Il se rend dans un sanctuaire. Une voix lui prédit que les dieux ne sont pas favorables à son clan, celui des Taira. Par un soir de pleine lune, il joue de la flûte avant de se jeter à l'eau pour ne pas avoir à subir le déshonneur de la défaite. Son fantôme apparait alors à sa femme. Mais on ne revient pas de l'enfer. Ces représentations étaient soutenues par les classes guerrières bien que le conte dénigre l'esprit guerrier.

\section{Musique}

17 Les commentaires suivants portent sur la musique. Le rythme est à huit temps auxquels s'ajoutent des silences. Les instruments sont accompagnés par la voix qui sert à transmettre les pensées. La flûte utilisée est faite en bambous particuliers dont on se servait pour soutenir les toits des vieilles fermes japonaises. Il a séché pendant 200 à 300 ans. Il est très dur, ce qui lui donne une sonorité très claire. La tonalité est délibérément faussée pour obtenir une sonorité particulière et personnelle comme celle de la voix humaine.

Les instruments à percussion sont au nombre de deux. Il y a tout d'abord un grand tambour dont la peau est en cuir de cheval (dos et croupe) et l'intérieur en bois de cerisier. Des cordelettes en lin tendent la peau. Avant d'entrer en scène, une heure auparavant, il faut chauffer le tambour avec du charbon de bois afin de serrer les cordelettes. Frapper avec les mains sur ce tambour est difficile à supporter lors de l'apprentissage. Ensuite il y a un petit tambour, en cuir de (jeune) cheval (ventre). Les cordelettes sont plus ou moins serrées, ce qui permet une grande variation de notes. On l'humidifie à l'aide de la bouche ouverte en soufflant dessus. Une démonstration s'ensuit.

\section{Musiciens}

- Makoto oHNO : flûtiste ;

- Atsushi UEDA : joueur de petit tambour tsuzumi ;

- Kazuyuki HARAOKA : joueur de grand tambour tsuzumi. 


\section{Costumes}

Haruhisa Kawamura présente ensuite des costumes. Les symboles sont très importants. Pour les hommes les motifs seront géométriques, des flèches pour les guerriers avec des contrastes de couleur. Les personnages de haute noblesse, hommes ou femmes, portent des vêtements sur lesquels sont dessinés des fleurs, des papillons, des éventails... Les femmes ont des drapés autour des hanches, le vêtement est échancré mais il y a toujours des dessous. Cela permet de modifier en permanence l'habit afin de créer un autre personnage. La façon dont l'habit est porté est significative. Un vêtement un peu lâche peut évoquer par exemple le déséquilibre émotionnel. Les acteurs ont, dans le dos, une pièce de bois pour jouer certains personnages (difficile à supporter). Cela leur donne plus de majesté. Il existe parfois cent combinaisons possibles pour un acteur voulant changer de personnage.

Démonstration de costumes

- Naoko KAWAMURA ;

- Chisato JUGE.

La soirée se termine par un passage célèbre de la pièce L'Araignée de la terre. Un guerrier, malade, est couché dans son lit. Un prêtre apparaît alors et l'attaque avec des toiles d'araignée. Au moment où le guerrier s'apprête à se défendre avec son épée, le prêtre, qui n'est que l'esprit d'une araignée, disparaît.

Cette présentation a-t-elle suffit pour sensibiliser le public? Le nô est un art spécifiquement japonais qu'il est difficile d'approcher. Même pour un Japonais, sa découverte ne peut se faire sans une éducation. On ne peut donc que féliciter les participants et les organisateurs d'avoir tenté celle-ci auprès d'un public occidental.

\section{NOTES}

1. Jean-Jacques Tschudin, Daniel Struve, La Littérature japonaise, coll « Que sais-je ? », 2008

\section{INDEX}

Mots-clés : nô, théâtre japonais

Keywords : nô, japanese theater

Palabras claves : nô, teatro japonés

Palavras-chave : nô, teatro japonês 
AUTEUR

RÉGIS FOUGÈRE

Université de Franche-Comté 